\title{
A Novel Aminoglycoside-modifying Enzyme from a Clinical Isolate of Acinetobacter
}

\author{
By J. E. DOWDING* \\ Department of Biochemistry, University of Leicester, Leicester LE1 7RH
}

(Received 7 September 1978)

\section{INTRODUCTION}

Resistance to the aminoglycoside-aminocyclitol group of antibiotics in clinical isolates of bacteria is commonly associated with the production of enzymes which can be shown to modify these compounds in vitro either by $N$-acetylation, $O$-phosphorylation or $O$-nucleotidylation (Benveniste \& Davies, 1973). This paper describes a strain of Acinetobacter which posseses a novel modifying enzyme of restricted substrate range. This enzyme appears to catalyse the $\mathrm{N}$-acetylation of only those aminoglycosides of the kanamycin-gentamicin group which bear a 2'-hydroxyl group.

\section{METHODS}

Bacterial strain. The organism used in these studies was a clinical isolate of Acinetobacter kindly provided by R. Warren of the Department of Bacteriology, New Addenbrooke's Hospital, Cambridge. It was resistant (minimum inhibitory concentration in $\mu \mathrm{g} \mathrm{ml}^{-1}$ ) to kanamycin ( > 512), gentamicin (128), amikacin, i.e. BBK8 (32), sisomicin (128), tobramycin (64) and neomycin and sensitive to streptomycin.

Preparation of bacteria-free extracts. Bacteria were grown and extracts prepared as described by Dowding (1977). Partially purified enzyme was prepared from crude extracts by chromatography on Sephadex G-100 followed by electrophoresis on polyacrylamide gels, both as previously described (Dowding, 1977).

Enzyme assays. Aminoglycoside-modifying enzyme was assayed by the phosphocellulose paper binding method as described by Haas \& Dowding (1975). Deacylase activity was monitored by using a Pye-Unicam SP1800 spectrophotometer to measure the increase in $A_{412}$ in the following reaction mixture (total vol. $1 \mathrm{ml}$ ): $10 \mu 10.01 \mathrm{M}$-acetyl-CoA, $20 \mu \mathrm{l} 0.02 \mathrm{M}-5,5^{\prime}$-dithiobis(2-nitrobenzoic acid) (DTNB), 10 to $50 \mu 1$ enzyme preparation and $0.05 \mathrm{M}-\mathrm{Tris} / \mathrm{HCl}, \mathrm{pH} 8.0$.

\section{RESULTS AND DISCUSSION}

The organism described here was examined to determine its mechanism of resistance to kanamycin and gentamicin. Preliminary experiments consistently yielded bacteria-free extracts with very low acetyltransferase activity. Attempts to induce higher levels of enzyme activity by growth in medium containing kanamycin $\left(10 \mu \mathrm{g} \mathrm{ml}^{-1}\right)$ were unsuccessful (C. $\mathrm{M}$. Graham, unpublished results). It was subsequently found that pre-incubation of crude extracts with acetyl-CoA followed by assay with kanamycin abolished detectable acetyltransferase activity. This suggested the presence in these extracts of an unspecified deacylating enzyme and this was confirmed using the DTNB assay (see Methods). All subsequent experiments were therefore performed using partially purified enzyme which contained no detectable deacylase activity.

Kinetics of the acetylation of a number of aminoglycosides are shown in Fig. 1. Other potential substrates which were not acetylated are omitted for the sake of clarity. They include gentamicins $C_{2}$ and $C_{1}$, neomycin $B$, tobramycin, ribostamycin, butirosin and lividomycin A. It is clear from these results that there are only three good substrates for the

\footnotetext{
* Present address: Department of Pharmacology, University of Cambridge Medical School, Cambridge CB2 2QD.
} 


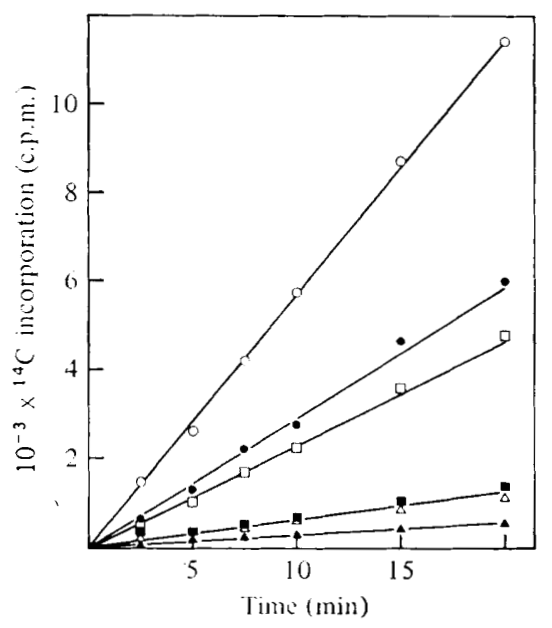

Fig. 1. Kinetics of acetylation of various aminoglycosides using partially purified enzyme: $\bigcirc$, kanamycin A; $\boldsymbol{O}$, gentamicin B; $\square$, amikacin; $\mathbf{a}$, sisomicin; $\triangle$, kanamycin $\mathrm{B} ; \boldsymbol{\Delta}$, gentamicin $\mathrm{C}_{1 \mathrm{a}}$.

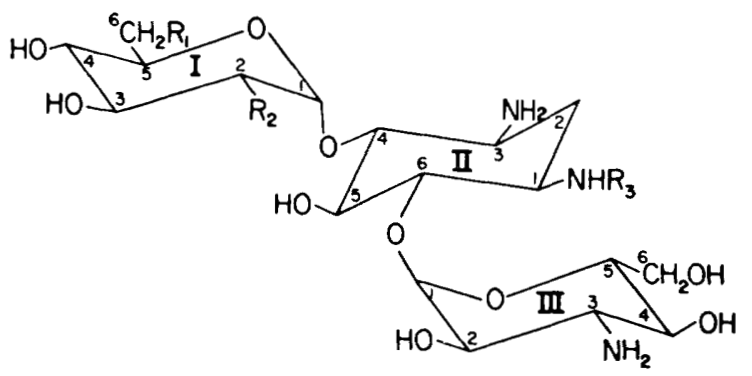

$\begin{array}{llll} & \mathrm{R}_{1} & \mathrm{R}_{2} & \mathrm{R}_{3} \\ \text { Kanamycin A } & \mathrm{NH}_{2} & \mathrm{OH} & \mathrm{H} \\ \text { Kanamycin B } & \mathrm{NH}_{2} & \mathrm{NH}_{2} & \mathrm{H} \\ \text { Kanamycin C } & \mathrm{OH} & \mathrm{NH}_{2} & \mathrm{H} \\ \text { Amikacin } & \mathrm{NH}_{2} & \mathrm{OH} & \mathrm{CO}-\mathrm{CH}(\mathrm{OH})-\mathrm{CH}_{2}-\mathrm{CH}_{2}-\mathrm{NH}_{2}\end{array}$

Fig. 2. Structures of the kanamycins.

enzyme among those tested, namely kanamycin $\mathrm{A}$, its derivative amikacin and gentamicin B. These compounds all have a hydroxyl group at position 2 of ring I (see Fig. 2), suggesting that the enzyme is either an aminoglycoside- $O$-acetyltransferase or an $N$-acetyltransferase which requires a 2 '-OH group for activity. All previously described aminoglycoside acetyltransferases catalyse $N$-acetylation (Haas \& Dowding, 1975) and an attempt was therefore made to distinguish between the two possibilities by treating the reaction product $\left(\left[{ }^{14} \mathrm{C}\right]\right.$ acetyl kanamycin A) with $1 \mathrm{M}-\mathrm{NaOH}$. This procedure results in the hydrolysis of $O$-acetyl but not $\mathrm{N}$-acetyl groups (Shaw, 1967). No such hydrolysis was detected, in spite of repeated attempts under a variety of conditions and it was concluded that the enzyme described is an $N$-acetyltransferase which requires a $2^{\prime}$-hydroxyl group for significant activity.

Chromatography on Sephadex G-100 with various standards indicated that the enzyme has an approximate molecular weight of 41000 . Acetylation of kanamycin A by the enzyme in vitro was inhibited by the structurally related aminoglycosides kanamycin $B$ and tobramycin and the less-related compound neomycin B, but not by streptomycin. 
A number of organisms are now known in which possession of a modifying enzyme with a given substrate specificity does not correlate with the observed resistance phenotype of the strain (Courvalin \& Davies, 1977). It is thus difficult to judge whether the low, but significant, rates of acetylation of sisomicin and kanamycin B observed are sufficient to confer resistance to these antibiotics in vivo. The mechanisms of resistance to gentamicin, tobramycin and neomycin in this strain remain undetermined; repeated examination of crude extracts failed to reveal any of the enzymes which are currently known to modify these compounds.

I wish to thank Bob Hedges for helpful discussions and the Medical Research Council for financial support. This study was initiated by Mark Graham as part of a research project in the Department of Pharmacology, University of Cambridge Medical School.

\section{REFERENCES}

Benveniste, R. \& Davies, J. (1973). Mechanisms of antibiotic resistance in bacteria. Annual Review of Biochemistry 42, 471-506.

Courvalin, P. \& Davies, J. (1977). Plasmidmediated aminoglycoside phosphotransferase of broad substrate range that phosphorylates amikacin. Antimicrobial Agents and Chemotherapy 11, 619-624.

DowDING, J. E. (1977). Mechanisms of gentamicin resistance in Staphylococcus aureus. Antimicrobial Agents and Chemotherapy 11, 47-50.

HaAs, M. J. \& Dowding, J. E. (1975). Aminoglycoside-modifying enzymes. Methods in Enzymology 43, 611-628.

SHAw, W. V. (1967). The enzymatic acetylation of chloramphenicol by extracts of $\mathbf{R}$ factor-resistant Escherichia coli. Journal of Biological Chemistry 242, 687-693. 